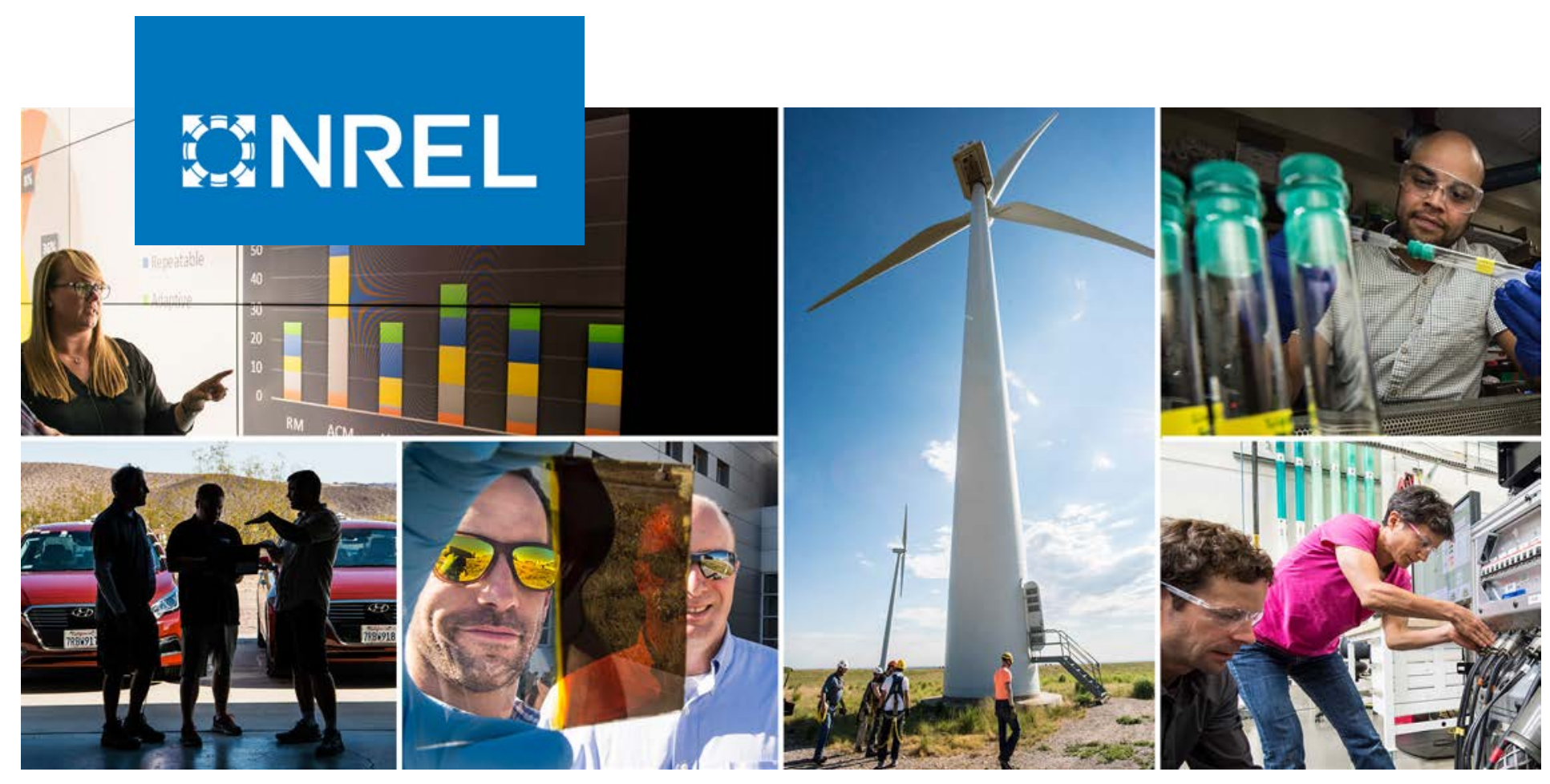

\title{
Expanding Community Shared Solar in New York City: Analysis of Barriers and Policy Pathways
}

Eric O'Shaughnessy

National Renewable Energy Laboratory

NREL is a national laboratory of the U.S. Department of Energy Office of Energy Efficiency \& Renewable Energy

Operated by the Alliance for Sustainable Energy, LLC

This report is available at no cost from the National Renewable Energy Laboratory (NREL) at www.nrel.gov/publications.

\section{Technical Report}

NREL/TP-6A20-72186

February 2019 


\title{
GNREL
}

\section{Expanding Community Shared Solar in New York City: Analysis of Barriers and Policy Pathways}

\author{
Eric O'Shaughnessy
}

National Renewable Energy Laboratory

\section{Suggested Citation}

O'Shaughnessy, Eric. 2019. Expanding Community Shared Solar in New York City: Analysis of Barriers and Policy Pathways. Golden, CO: National Renewable Energy Laboratory. NREL/TP-6A20-72186. https://www.nrel.gov/docs/fy19osti/72186.pdf.

NREL is a national laboratory of the U.S. Department of Energy Office of Energy Efficiency \& Renewable Energy Operated by the Alliance for Sustainable Energy, LLC

This report is available at no cost from the National Renewable Energy Laboratory (NREL) at www.nrel.gov/publications.

Contract No. DE-AC36-08GO28308
Technical Report NREL/TP-6A20-72186 February 2019

National Renewable Energy Laboratory 15013 Denver West Parkway Golden, CO 80401 303-275-3000 • www.nrel.gov 


\section{NOTICE}

This work was authored by the National Renewable Energy Laboratory, operated by Alliance for Sustainable Energy, LLC, for the U.S. Department of Energy (DOE) under Contract No. DE-AC36-08GO28308. Funding provided by U.S. Department of Energy Office of Energy Efficiency and Renewable Energy Solar Energy Technologies Office. The views expressed herein do not necessarily represent the views of the DOE or the U.S. Government.

This report is available at no cost from the National Renewable Energy Laboratory (NREL) at www.nrel.gov/publications.

U.S. Department of Energy (DOE) reports produced after 1991 and a growing number of pre-1991 documents are available free via www.OSTI.gov.

Cover Photos by Dennis Schroeder: (clockwise, left to right) NREL 51934, NREL 45897, NREL 42160, NREL 45891, NREL 48097, NREL 46526.

NREL prints on paper that contains recycled content. 


\section{Foreword}

The New York City Mayor's Office of Sustainability seeks to identify policy pathways to support a local and scalable community shared solar market. This memo summarizes the key challenges to the New York City community shared solar and the existing policy landscape.

Several tax incentive and other policy pathways are analyzed. The results suggest that supportive New York City policies could yield community shared solar deployment on the order of megawatts per year, resulting in tens of thousands of megawatt-hours of community shared solar output and generating millions of dollars in local economic activity. 


\section{Preface}

This work was authored by the National Renewable Energy Laboratory (NREL), operated by Alliance for Sustainable Energy, LLC, for the U.S. Department of Energy (DOE) under Contract No. DE-AC36-08GO28308. Funding provided by the DOE Office of Energy Efficiency and Renewable Energy Solar Energy Technologies Office.

The Solar Technical Assistance Team (STAT) Network is a project of the DOE and is implemented by NREL. The STAT Network provides credible and timely information to policymakers and regulators for the purpose of solar technology and policy-related decision support.

The New York City Mayor's Office of Sustainability requested assistance in developing costbenefit considerations and analysis to be used in evaluating the budgetary case for expanding incentives to support community shared solar installations in New York City. The New York City Mayor's Office of Sustainability is specifically interested in rooftop acquisition and optimizing scarce surface area for distributed solar deployment.

This analysis was conducted to meet an immediate need and was based on the best information the analysts had available within time constraints. This memo is intended to be a starting point for additional research and analysis into solar options for the New York City Mayor's Office of Sustainability and does not constitute a comprehensive roadmap for solar deployment.

The views expressed in this report do not necessarily represent the views of the DOE or the U.S. Government. This document was prepared as an account of work sponsored by an agency of the United States government. Neither the United States government nor any agency thereof, nor any of their employees, makes any warranty, express or implied, or assumes any legal liability or responsibility for the accuracy, completeness, or usefulness of any information, apparatus, product, or process disclosed, or represents that its use would not infringe privately owned rights. Reference herein to any specific commercial product, process, or service by trade name, trademark, manufacturer, or otherwise does not necessarily constitute or imply its endorsement, recommendation, or favoring by the United States government or any agency thereof. The views and opinions of authors expressed herein do not necessarily state or reflect those of the United States government or any agency thereof. 


\section{Acknowledgments}

For their collaboration on this project, we would like to thank the following individuals from the New York City Mayor's Office of Sustainability: Thomas Hutton, Eleanor Kahn, Benjamin Mandel, and Susanne DesRoches. For their thoughtful review of this work, we would like to thank Shamara Collins (DOE), Kyle Fricker (DOE), Nate Hausman (Clean Energy States Alliance), and Alison Holm (NREL). 


\section{List of Acronyms}

CSS

DOE

DOF

community shared solar

EDC

Department of Energy

$\mathrm{kW}$

Department of Finance

MW

Economic Development Corporation

kilowatt

megawatt

National Renewable Energy Laboratory

net present value

NPV

New York City

NYC

property tax abatement

STAT

Solar Technical Assistance Team 


\section{Table of Contents}

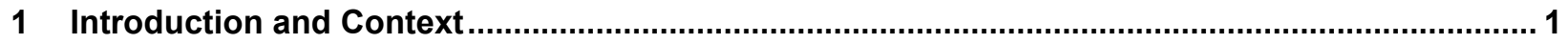

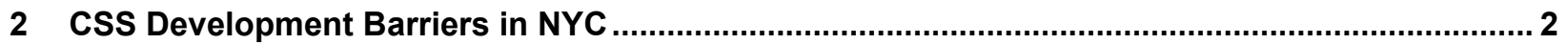

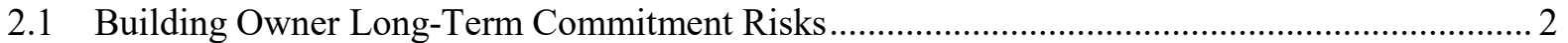

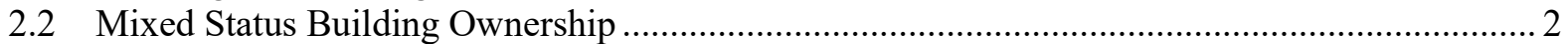

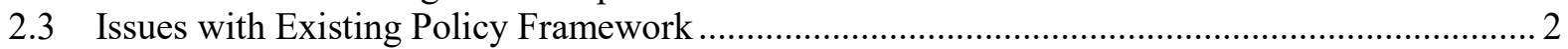

3 Policy Analysis: Tax Incentives to Support NYC CSS Market ....................................................... 4

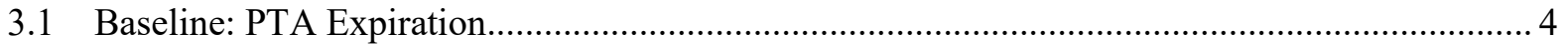

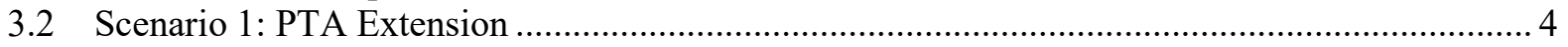

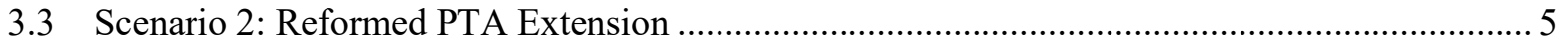

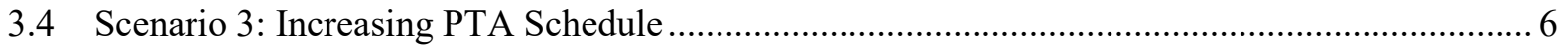

3.5 Scenario 4: Commercial Expansion Program Incentives ............................................................. 7

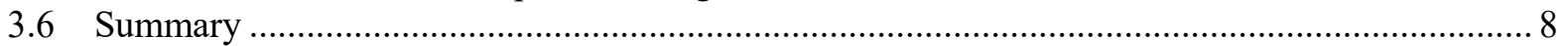

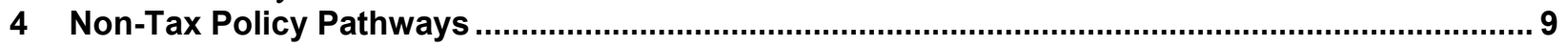

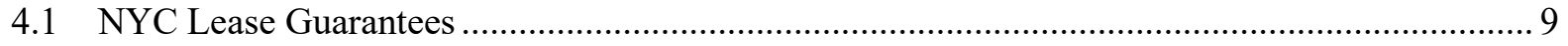

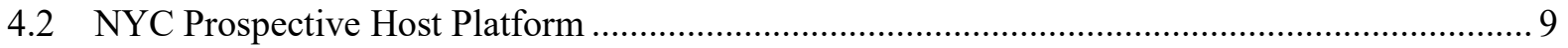

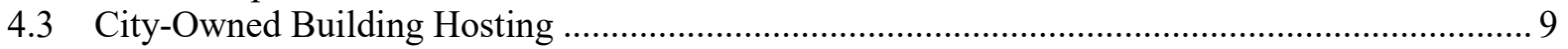

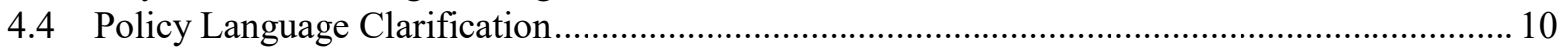

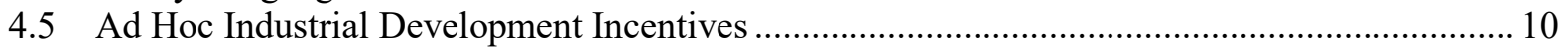

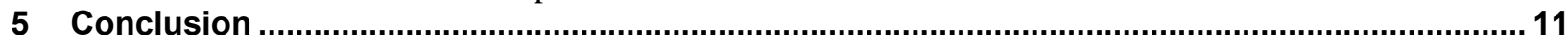

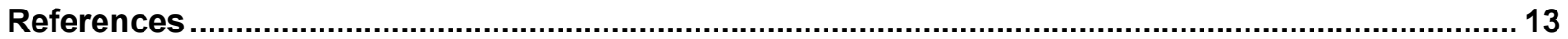

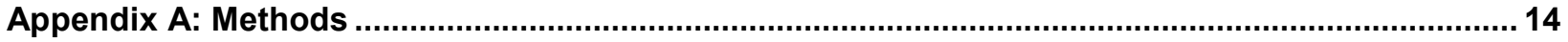

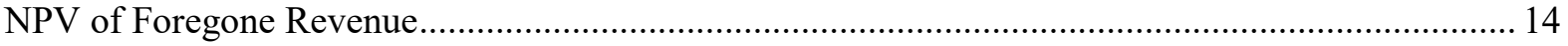

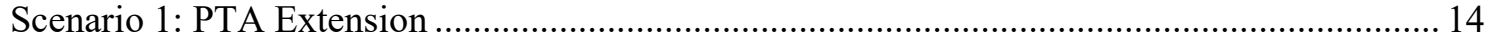

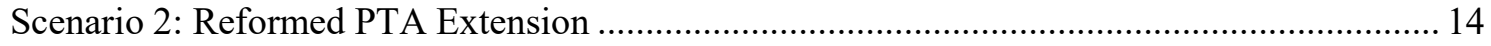

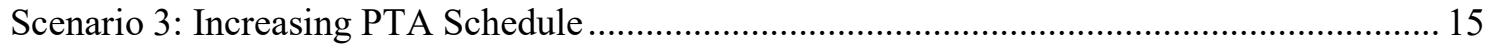

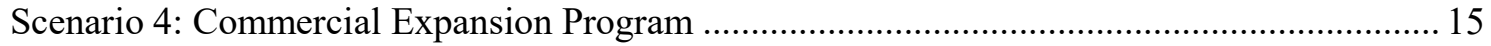

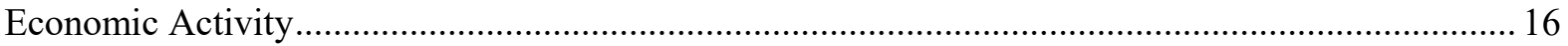




\section{List of Figures}

Figure 1. Summary of tax incentive policy impacts (left pane) and costs (right pane)............................ 8

\section{List of Tables}

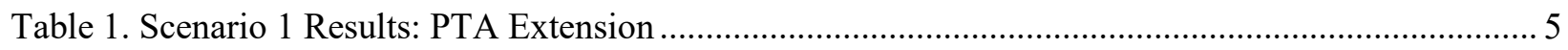

Table 2. Scenario 2 Results: Reformed PTA Extension ................................................................. 5

Table 3. Scenario 3 Results: Increasing PTA Schedule...................................................................... 6

Table 4. Scenario 4 Results: Commercial Expansion Program ................................................................ 7

Table 5. Summary of Tax Incentive Policy Cost and Impacts................................................................ 11 


\section{Introduction and Context}

Community shared solar $(\mathrm{CSS})^{1}$ could be an effective way to improve customer participation in the New York City (NYC) solar market, the most densely populated urban environment in the United States (US Census 2012). Most residents of New York City are renters - about 63\% of the housing stock are rental units - and many homeowners lack access to rooftop space in multifamily buildings (U.S. Census 2015; NYC 2018). These conditions make NYC an ideal subscriber $^{2}$ base for CSS. However, potential hosts and solar developers face unique challenges in siting CSS projects in NYC. Due to competing interests for valuable real estate and re-zoning trends, CSS has failed to gain traction in NYC. The NYC Mayor's Office of Sustainability seeks to identify policy pathways that could overcome these challenges and grow the NYC CSS market.

New York State policy allows for CSS projects that are less than 5 megawatts (MW) in size and which have at least 10 subscribers (NY PSC 2015). ${ }^{3}$ The 10 -subscriber minimum is waived for projects on multi-family buildings. The CSS policy allows for commercial and industrial customers to subscribe to up to $40 \%$ of project capacity, limiting all other subscribers to less than 25 kilowatts (kW) per subscription. As of April 2018, about 4 MW of capacity across 13 CSS projects had been installed in New York State. ${ }^{4}$ Over $700 \mathrm{MW}$ in 317 projects are in the pipeline in New York State. CSS has gained less traction in NYC, with 25 projects in the pipeline, representing about $8.5 \mathrm{MW}$ of capacity. At the time of writing, five CSS projects were in some state of construction or completion, representing about $3 \mathrm{MW}$ of NYC CSS project capacity. ${ }^{5}$

\footnotetext{
${ }^{1}$ The term "community shared solar" is used throughout to refer to projects where output from a central solar photovoltaic system is credited to multiple accounts. This term is commonly used in New York City, though community shared solar is often referred to as community distributed generation in New York State.

2 The term "subscriber" is commonly used to describe retail electricity customers that "subscribe" to a specified capacity or output from a CSS array.

${ }^{3}$ As part of New York's Reforming the Energy Vision (REV), CSS projects are now eligible for value of distributed energy net metering.

${ }^{4}$ All references to New York solar data are based on New York State Energy Research and Development Authority's Open NY Database. See: https://data.ny.gov/browse?DatasetInformation Agency $=$ Energy + Research + and + Development + Authority

${ }^{5}$ Based on conversations with project developers.
} 


\section{CSS Development Barriers in NYC}

The NYC Mayor's Office of Sustainability and other stakeholders have identified site host acquisition as a key challenge for NYC CSS development. CSS models require a building or landowner to "host" a CSS array. Hosts are typically compensated through site lease payments. New York State's community distributed generation program rules require CSS subscribers be located in the same utility service territory and NY-ISO load zone as the project. This effectively precludes New York City residents from subscribing to CSS projects upstate. NYC's urban environment provides limited opportunities for ground mount-capable sites, such that CSS project capacities are generally limited by available rooftop space. In NYC, potential hosts include owners of large commercial and industrial buildings with rooftops large enough to support systems of $200 \mathrm{~kW}$ or more of capacity. These rooftop spaces are often not utilized or under-utilized, such that potential rooftop lease revenue should be attractive to building owners. However, interviews with the NYC Mayor's Office of Sustainability and other stakeholders revealed several challenges in inducing building owners to host solar systems: building owner long-term commitment risks, mixed status building ownership, and issues with the existing CSS policy framework. ${ }^{6}$

\subsection{Building Owner Long-Term Commitment Risks}

Potential building hosts are generally averse to long-term lease contracts for rooftop space. This aversion stems from NYC's dynamic real estate environment. The potential for future re-zoning and urban development means that many commercial and industrial sites could be converted into more lucrative residential uses in the near future. Prospective hosts bear the risk of delaying or foregoing lucrative site re-purposing by tying up rooftop space in 10- to 20-year solar leases. As a result, prospective hosts may demand higher lease rates to shift some of the risk burden onto developers and system owners. Alternatively, prospective hosts may demand shorter-term contracts that undermine project economics. In both cases, building owner aversion to long-term rooftop commitments reduce interest in CSS hosting and impede NYC CSS deployment.

\subsection{Mixed Status Building Ownership}

Several stakeholders stated that the mixed abilities of building owners to leverage available tax incentives increases site acquisition costs. As discussed further in the following section, NYC's primary solar incentive uses a tax abatement that is unavailable to tax-exempt building owners (e.g., non-profits). Other building owners may have insufficient tax liability to fully monetize available tax incentives. Developers generally do not know the tax status of building owners. Hence, developers inefficiently invest resources in exploring potential sites that are ultimately not viable due to tax status.

\subsection{Issues with Existing Policy Framework}

In addition to federal and state incentives for solar, NYC has enacted policies to support solar development within the city (NYSERDA 2018). For example, building owners with a property

\footnotetext{
${ }^{6}$ Interviews have been conducted with CleanChoice Energy, Daroga Power (developer), Gotham Community Solar, the New York City Economic Development Corporation, On-Force Solar, SolarOne, and a building manager at an NYC CSS site. Feedback has also been gathered from experts at the City University of New York and documents obtained from the NYC Department of Finance. Further interviews have been planned for this project.
} 
tax liability that place a solar photovoltaic (PV) system "in service in connection with an eligible building" are eligible for the NYC property tax abatement (PTA). ${ }^{7}$ The PTA is worth $5 \%$ of the installed system costs per year for four years, capped at $\$ 62,500 /$ year or $\$ 250,000$ in total. The PTA is applied after all other New York State rebates have been deducted from the installed cost. NYC stopped accepting applications for the existing PTA on December 31, 2018, as scheduled. Stakeholders reported that a PTA extension has been discussed at the state and city levels, but the PTA is inactive at the time of publication.

The NYC Mayor's Office of Sustainability and other stakeholders have identified at least two issues with the existing PTA framework. First, the PTA cap at $\$ 62,500 /$ year may render the incentive value too marginal to attract large industrial building hosts. Second, the language is vague enough to create possible confusion around PTA eligibility for CSS projects. The PTA accrues to the building owner rather than the solar PV system owner and appears to allow nonsystem owner hosts to accrue the PTA. However, the restriction that the system be "in connection with an eligible building" may be difficult to satisfy for CSS projects where subscribers are not necessarily building occupants.

Stakeholder feedback indicates that further policy ambiguity may exist concerning system ownership, sales of system output, and regulation. New York State exempts solar PV system owners from utility regulation. ${ }^{8}$ This language protects PV system owners from utility regulation in cases where system output is "distributed solely from one or more of such [systems] to users located at or near a project site." Ambiguity in what constitutes distribution "near" the project site could complicate CSS project development, given that CSS subscribers may not reside near the project site. Indeed, NYC regulators rejected one proposed CSS project on the grounds that the project qualified as a "utility use." "Further, rooftop solar systems have been treated as separate property lots for taxation purposes in some cases, disqualifying the building owner from PTA eligibility.

\footnotetext{
${ }^{7}$ New York Consolidated Laws, Real Property Tax Law, Article 4, Title 4-C. Eligible building refers to property tax class one, class two, or class four building in cities larger than one million people. See http://public.leginfo.state.ny.us/lawssrch.cgi?NVLWO:.

${ }^{8}$ New York Consolidated Laws, Public Service Law - PBS §2.13. http://codes.findlaw.com/ny/public-servicelaw/pbs-sect-2.html.

${ }^{9}$ Based on conversation with the project developer Daroga Power.
} 


\section{Policy Analysis: Tax Incentives to Support NYC CSS Market}

Four tax policy pathways to expand NYC CSS are analyzed. Each policy is assessed against a hypothetical baseline scenario where the PTA expires, and no additional policies are implemented. Policy impacts are presented in terms of additional installed CSS capacity (MW/year), additional CSS output (MWh/year) ${ }^{10}$ foregone tax revenue $(\$ \mathrm{M} /$ year), and additional economic activity ( $\$ \mathrm{M} / \mathrm{year})$. Ranges are presented to avoid over-stating confidence in point estimates. The ranges should roughly approximate low-and high-end estimates of policy impacts. See "Appendix A: Methods" for more detailed information about the approaches to the policy analysis.

\subsection{Baseline: PTA Expiration}

Five projects representing about $3 \mathrm{MW}$ of capacity were due to come online in NYC in the first half of 2018 under the existing PTA. One developer had an additional $4 \mathrm{MW}$ in some stage of construction as of early 2018, suggesting that total installed capacity in 2018 could be as high or higher than $7 \mathrm{MW} .{ }^{11}$ Based on these data, it is assumed that $3 \mathrm{MW} /$ year (5 projects) represents a low-end estimate of annual installation rates and that $7 \mathrm{MW} /$ year (12 projects) represents a highend estimate of installation rates under a PTA extension.

The baseline assumes that the PTA expires at the end of 2018, as scheduled. One developer estimated that about half of the project pipeline would be economically infeasible without the PTA, while another developer stated that the entire project pipeline depends on the PTA. Conservatively, if about half of CSS projects would remain economically viable with a PTA expiration, it is assumed that a range of $1.5 \mathrm{MW} / \mathrm{year}$ ( 2.5 projects) to $3.5 \mathrm{MW} /$ year (6 projects) would be installed if the PTA expires. This deployment range serves as the baseline scenario.

\subsection{Scenario 1: PTA Extension}

Scenario 1 assumes the PTA is extended as is. Building on the discussion in the baseline, a PTA extension could support an additional $1.5 \mathrm{MW} /$ year (2.5 projects) to $3.5 \mathrm{MW} /$ year (6 projects) of NYC CSS deployment. Table 1 presents results of the policy analysis. It is estimated that the PTA extension would cost about $\$ 1 \mathrm{M}-\$ 3 \mathrm{M} /$ year in foregone tax revenue and generate $\$ 1 \mathrm{M}$ $\$ 3 \mathrm{M} /$ year in economic activity.

\footnotetext{
${ }^{10}$ Capacity is converted to output based on a capacity factor of $13 \%$, the same capacity factor applied in the NYSERDA Open NY Database for NYC CSS projects.

${ }^{11}$ These estimates are based on data collected during the period of analysis in 2018 .
} 
Table 1. Scenario 1 Results: PTA Extension

\begin{tabular}{llll}
\hline $\begin{array}{l}\text { Additional Installed } \\
\text { Capacity (MW/year) }\end{array}$ & $\begin{array}{l}\text { Additional Output } \\
\text { (MWh/year) }\end{array}$ & $\begin{array}{l}\text { Foregone Tax } \\
\text { Revenue (\$M/year) }\end{array}$ & $\begin{array}{l}\text { Economic Activity } \\
\text { (\$M/year) }\end{array}$ \\
\hline $1.5-3.5$ & $1,700-4,000$ & $1-3$ & $1-3$ \\
\hline
\end{tabular}

\subsection{Scenario 2: Reformed PTA Extension}

Scenario 2 assumes the PTA is extended, with an increased duration from 4 to 10 years, and the PTA cap is removed. Based on stakeholder feedback, these PTA reforms would have significant impacts on the NYC CSS market. Extending the PTA duration would increase the lifetime value of the PTA to building owners and could allay re-zoning risk. Removing the PTA cap could improve project economics on large rooftops where project costs exceed the existing cap. Hence a reformed PTA extension could increase the number of viable projects and increase average project size.

To generate a low-end estimate, a no-impact case assumes that the reformed PTA extension would have no incremental impact on NYC CSS capacity relative to the simple PTA extension (Scenario 1). To generate a high-end estimate, a high-impact case assumes that the reformed PTA extension increases deployment by a factor of 2.3 , the estimated difference in value to a building owner between the reformed PTA and the existing PTA for a hypothetical $500 \mathrm{~kW}$ system (see Appendix A: Methods).

Table 2 summarizes the analytical results for Scenario 2 based on these two cases. The no-impact case represents a worst-case scenario where the PTA reforms have no effect on deployment but result in increased foregone revenue to the city. The high-impact case represents a situation where the PTA reforms increase deployment while incurring the cost of increased foregone tax revenue. In both cases, foregone tax revenues are higher than under a simple PTA extension, given that the PTA accrues over a longer timeframe and that the PTA cap has been removed. In the high-impact case, these additional costs may be justified by a significant increase in CSS output: we estimate that CSS output would increase by about $260 \%$ in the high-impact case for the reformed PTA extension relative to a simple PTA extension. The reformed PTA also increases incremental economic activity by about a factor of 4 . However, foregone tax revenues exceed benefits from increased economic activity.

Table 2. Scenario 2 Results: Reformed PTA Extension

\begin{tabular}{lllll}
\hline Policy Impact & $\begin{array}{l}\text { Additional } \\
\text { Installed Capacity } \\
\text { (MW/year) }\end{array}$ & $\begin{array}{l}\text { Additional } \\
\text { Output } \\
\text { (MWh/year) }\end{array}$ & $\begin{array}{l}\text { Foregone Tax } \\
\text { Revenue } \\
\text { (\$M/year) }\end{array}$ & $\begin{array}{l}\text { Economic Activity } \\
\text { (\$M/year) }\end{array}$ \\
\hline None & $1.5-3.5$ & $1,700-4,000$ & $3-6$ & $1-3$ \\
High & $5.5-12.5$ & $6,300-14,200$ & $6-14$ & $4-9$ \\
\hline
\end{tabular}




\subsection{Scenario 3: Increasing PTA Schedule}

Scenario 3 assumes that the PTA is extended, the PTA duration is extended from 4 to 10 years, the PTA cap is removed, and that the PTA rate is adjusted to the following schedule:

\begin{tabular}{|c|c|c|c|c|c|c|c|c|c|c|}
\hline Year & 1 & 2 & 3 & 4 & 5 & 6 & 7 & 8 & 9 & 10 \\
\hline PTA & $1 \%$ & $2 \%$ & $3 \%$ & $4 \%$ & $5 \%$ & $5 \%$ & $5 \%$ & $5 \%$ & $5 \%$ & $5 \%$ \\
\hline
\end{tabular}

The increasing schedule developed here is provided for illustrative purposes. Policymakers and stakeholders could work together to design an optimal schedule. The increasing schedule would have several benefits. First, the increasing schedule would reduce the host's risk, given that the penalty of breaking the lease early is lower when PTA receipts are lower in the early years of the term. ${ }^{12}$ Second, the increasing schedule protects NYC's investment by distributing fewer abatements in the early years of the lease in the event that the host breaks the lease and defaults on the penalty. Tax abatements in the early years would generally be less than the abatement cap (\$62,500/year) under the existing PTA. Third, the increasing schedule incentivizes hosts to keep the property in its current use for the full PTA term to realize the higher abatement at the end of the term. Finally, the increasing schedule could result in some beneficial self-selection, given that building owners that are less likely to break the lease would be more likely to select into a program with an increasing incentive schedule.

To generate a low-end estimate, a no-impact case assumes that the increasing PTA schedule would have no incremental impact on NYC CSS capacity relative to the simple PTA extension (Scenario 1). To generate a high-end estimate, a high-impact case assumes that the increasing PTA schedule increases deployment by a factor of 1.8, the estimated difference in value to a building owner between the increasing PTA and the existing PTA for a hypothetical $500 \mathrm{~kW}$ system (see Appendix A: Methods).

Table 3 presents the analytical results for the increasing PTA. Policy impacts in terms of additional capacity, output, and economic activity are the same in the increasing PTA as in the reformed PTA (Scenario 2). However foregone tax revenues are lower in the increasing PTA, given that PTA outlays are lower in the early years of the PTA term.

Table 3. Scenario 3 Results: Increasing PTA Schedule

\begin{tabular}{lllll}
\hline Policy Impact & $\begin{array}{l}\text { Additional } \\
\text { Installed Capacity } \\
\text { (MW/year) }\end{array}$ & $\begin{array}{l}\text { Additional } \\
\text { Output } \\
\text { (MWh/year) }\end{array}$ & $\begin{array}{l}\text { Foregone Tax } \\
\text { Revenue } \\
\text { (\$M/year) }\end{array}$ & $\begin{array}{l}\text { Economic Activity } \\
\text { (\$M/year) }\end{array}$ \\
\hline Low & $1.5-3.5$ & $1,700-4,000$ & $2-5$ & $1-3$ \\
High & $3.5-9.5$ & $4,000-10,800$ & $4-9$ & $3-7$ \\
\hline
\end{tabular}

\footnotetext{
${ }^{12}$ NYC may implement a break clause dictating that hosts must re-pay some portion of the PTA if the host breaks the lease and decommissions the system during the PTA term.
} 


\subsection{Scenario 4: Commercial Expansion Program Incentives}

Scenario 4 assumes that the PTA is replaced by a program allowing rooftop PV lessees to capitalize on Commercial Expansion Program incentives. The Commercial Expansion Program offers property tax abatements to building owners that induce tenants to lease and use commercial and industrial spaces in certain areas of NYC. The Commercial Expansion Program abatement is equal to $\$ 2.5$ per square foot of leased space for 10 years. There is no precedent to allow rooftop lessors to claim the Commercial Expansion Program, and the only application to our knowledge has been rejected by NYC. ${ }^{13}$ NYC could amend policy language to explicitly extend the Commercial Expansion Program to rooftop lessors. The rationale is that the site host (building owner) induces the development of unutilized rooftop space by allowing a lessee (developer) to lease and use the space for CSS development. CSS project development also stimulates direct and indirect economic activity through the installation of alternative energy systems that produce bill savings for subscribers.

To generate a low-end estimate, a no-impact case assumes that the Commercial Expansion Program would have no incremental impact on NYC CSS capacity relative to the simple PTA extension (Scenario 1). To generate a high-end estimate, a high-impact case assumes that the Commercial Expansion Program increases deployment by a factor of 3.6, the estimated difference in value to a building owner between the Commercial Expansion Program and the existing PTA for a hypothetical $500 \mathrm{~kW}$ system (see Appendix A: Methods).

Table 4 summarizes the analytical results for Scenario 4 based on these two cases. The lowimpact case represents a worst-case scenario where the Commercial Expansion Program has no effect on deployment but results in increased foregone revenue to the city. The high-impact case represents a situation where the Commercial Expansion Program increases deployment while incurring the cost of increased foregone tax revenue. In both cases, foregone tax revenues are higher than a simple PTA extension (Scenario 1) and the reformed PTA extensions (Scenarios 2 and 3). The high costs of the Commercial Expansion Program reflect the value of the incentives to the building owners. These high costs may be justified by increased CSS deployment: we estimate that CSS output would increase by about a factor of 7 in the high-impact Commercial Expansion Program case relative to a simple PTA extension, and that CSS output would increase by about $90 \%$ in the high-impact Commercial Expansion Program case relative to the highimpact case for the reformed PTA extensions. The Commercial Expansion Program also increases economic activity relative to all other scenarios.

Table 4. Scenario 4 Results: Commercial Expansion Program

\begin{tabular}{lllll}
\hline Policy Impact & $\begin{array}{l}\text { Additional } \\
\text { Installed Capacity } \\
\text { (MW/year) }\end{array}$ & $\begin{array}{l}\text { Additional } \\
\text { Output } \\
\text { (MWh/year) }\end{array}$ & $\begin{array}{l}\text { Foregone Tax } \\
\text { Revenue } \\
\text { (\$M/year) }\end{array}$ & $\begin{array}{l}\text { Economic Activity } \\
\text { (\$M/year) }\end{array}$ \\
\hline Low & $1.5-3.5$ & $1,700-4,000$ & $4-10$ & $1-3$ \\
High & $9.5-21.5$ & $10,800-24,500$ & $15-35$ & $7-15$ \\
\hline
\end{tabular}

${ }^{13}$ Based on conversations with and documents provided by project developer Daroga Power. 


\subsection{Summary}

Figure 1 summarizes the results of the policy analysis for the four tax incentive policies. The figure illustrates the ranges of incremental impacts relative to a baseline where the PTA expires at the end of 2018.
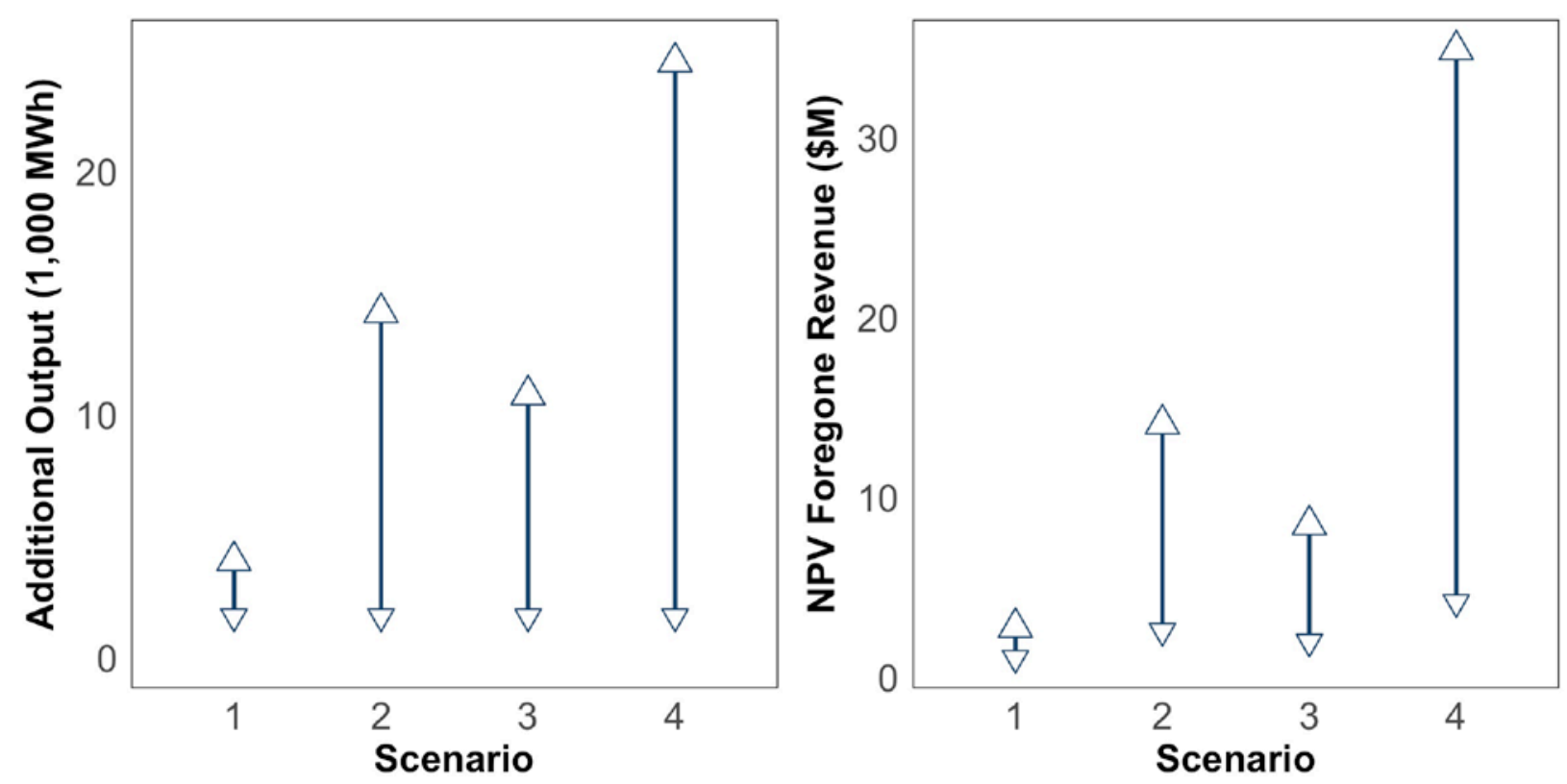

Figure 1. Summary of tax incentive policy impacts (left pane) and costs (right pane)

Scenario 1 represents the lowest-cost, lowest-impact policy pathway. A simple PTA extension would support ongoing CSS deployment consistent with current trends. Scenarios 2 and 3 maintain the existing PTA structure with reforms that both increase policy impact (in terms of CSS deployment) and increase costs. By providing lower abatements in the initial years of the PTA duration, the increasing PTA reduces the net present cost to NYC but also reduces the NPV to the building owner. As a result, Scenario 3 is a lower-cost, lower-impact PTA reform than Scenario 2.

Scenario 4 replaces the existing PTA structure with a PV Commercial Expansion Program. The Commercial Expansion Program is a more valuable incentive to building owners than the existing PTA or the reformed PTA structures in Scenarios 2 and 3. As a result, Scenario 4 has the greatest estimated impact on CSS deployment. However high values to building owners entail higher costs to NYC, making Scenario 4 the highest-cost, highest-impact tax incentive policy pathway.

The costs of the Commercial Expansion Program approach could be reduced by adjusting the incentive level, that is, by reducing the incentive level per square foot. However, the Commercial Expansion Program approach varies from the PTA approach in a way that would affect impacts and costs at any incentive level. Unlike the Commercial Expansion Program, the PTA amount correlates with system costs. As a result, the PTA level per watt installed declines as prices fall. Likewise, PTA levels are lower per watt installed for larger systems that reduce costs through economies of scale. In contrast, the Commercial Expansion Program level is set by rooftop space, so that foregone revenues do not fall if prices fall or if larger projects achieve economies of scale. Therefore, the costs and impacts of the Commercial Expansion Program approach should generally increase over time relative to the PTA. 


\section{Non-Tax Policy Pathways}

This section summarizes several non-tax policy pathways to support NYC CSS deployment. The policy pathways are discussed qualitatively and future work could attempt to quantify the impacts and costs of these non-tax policy pathways.

\subsection{NYC Lease Guarantees}

As an alternative approach to address long-term commitment risks, NYC or a financing institution such as the NY Green Bank or NYCEEC ${ }^{14}$ could act as guarantors for CSS projects. In this pathway, the guarantor would compensate the developer in the event that the host breaks the lease. The amount of the guarantee could decrease over time, such that compensation would be higher for leases broken earlier in the term. This structure could allow developers to pursue sites with higher lease rates, given the reduced risk of losses from a broken lease.

One possible structure would be to cover all developer losses in the event of re-zoning. In this structure, the developer could offer the building owner a lease with no damage clause in the event of re-zoning. This structure would eliminate the building owner's re-zoning risk and directly address re-zoning concerns as an implementation barrier. One developer estimated that such a guarantee would be worth about $\$ 25,000$ for each year of a broken lease for a $100-\mathrm{kW}$ system. Thus, in the event of a lease break in year 10, for example, program costs would be on the order of hundreds of thousands of dollars for relatively small systems, and on the order of millions of dollars for large systems. To reduce program costs, the guarantee could be offered as an insurance product. The guarantor would sell the guarantee to the developer for some up-front premium.

\subsection{NYC Prospective Host Platform}

Several stakeholders stated that finding suitable hosts was the primary barrier to NYC CSS deployment. Tax incentives partly address this challenge by increasing building owner incentives to become site hosts. However, project developers still struggle to contact suitable hosts even with the existing PTA. Several stakeholders argued that NYC could more directly address this challenge by serving as an information broker. NYC could publish information about building host suitability in an open online platform. The platform could include information about rooftop size and condition, building owner tax status, and building owner lease demands (e.g., short- or long-term lease). Such an online platform could reduce project developer site acquisition costs and ultimately improve project economics.

\subsection{City-Owned Building Hosting}

NYC has committed to deploying $100 \mathrm{MW}$ of PV on city-owned buildings by 2025. NYC could carve out some part of that goal for CSS deployment on city-owned buildings. This approach could yield several CSS projects while circumventing several of the challenges associated with privately-owned building site acquisitions. The approach could also generate economic benefits for NYC. NYC estimates that city-owned PV deployment could generate \$8 million in annual energy cost savings (City of New York 2017). However, these savings are limited by the fact that

\footnotetext{
${ }^{14}$ NYCEEC is a local financier specializing in projects that reduce building energy use or greenhouse gas emissions.
} 
city-owned buildings pay relatively low volumetric electricity rates $(\$ / \mathrm{kWh})$. Rather than generating savings through consuming PV output, NYC could potentially generate more revenue by leasing city-owned rooftop space to CSS developers. A city-owned building hosting policy could be implemented in tandem with tax incentive policies to partially offset the costs of foregone tax revenues.

\subsection{Policy Language Clarification}

Several stakeholders suggested that policy ambiguity impedes NYC CSS deployment. NYC authorities may not be familiar with regulations that exempt CSS projects from "utility use" classifications. Further, CSS systems may be treated as separate tax lots, undermining the ability of building owners to use tax incentives. Existing or reformed tax incentive language could clarify that CSS project owners are to be regulated as project sponsors exempted from utility use classifications (NY PSC 2015). Existing or reformed tax incentives could also specify that rooftop space and CSS projects are to be treated under the same tax lot as the host building.

\subsection{Ad Hoc Industrial Development Incentives}

The New York Economic Development Corporation (EDC) administers various programs to incentivize commercial and industrial development. EDC has broad authority to provide tax incentives for development projects with approval from the New York Department of Finance (DOF). EDC can also provide incentives on an ad hoc basis without DOF approval.

Conversations with EDC suggest that ad hoc incentives could be extended to rooftop solar systems in certain cases. 


\section{Conclusion}

NYC's large prospective subscriber base could support a scalable and local CSS market. However, project developers struggle to identify suitable host sites and to induce building owners to lease rooftop space for CSS deployment. Site acquisition challenges are driven in part by a scarcity of viable host sites, but also by NYC's dynamic real estate environment where rezoning trends add risks to CSS hosting. Lease revenues and tax incentives may allay these risks, though existing tax incentives have only yielded a small CSS market to date.

This memo examines tax incentive and other policy pathways to support the NYC CSS market. Table 5 summarizes the analytical results of the tax incentive pathways. Intuitively, policy impact correlates with policy costs: tax incentive policies increase CSS deployment at the cost of foregone tax revenue. NYC may develop hybrid policies that increase the cost-effectiveness of tax policies. For instance, an increasing Commercial Expansion Program schedule may yield some of the higher impacts of the Commercial Expansion Program incentive while also reducing foregone tax revenues through an increasing abatement schedule. NYC could also play the role of information broker by providing information to developers about suitable host sites. Other policy pathways include lease guarantees, city-owned building hosting, and ad hoc industrial development incentives.

Table 5. Summary of Tax Incentive Policy Cost and Impacts

\begin{tabular}{|c|c|c|}
\hline Policy & Cost & Impact \\
\hline PTA extension & $\begin{array}{l}\text { Low: PTA is capped and } \\
\text { duration is limited to } 4 \text { years }\end{array}$ & $\begin{array}{l}\text { Low: The low value of the PTA } \\
\text { and the PTA cap limit } \\
\text { applicability for large projects }\end{array}$ \\
\hline Reformed PTA extension & $\begin{array}{l}\text { Moderate-high: PTA cap } \\
\text { removal and extension to } 10 \\
\text { years increases costs relative to } \\
\text { simple PTA extension }\end{array}$ & $\begin{array}{l}\text { Moderate-high: Higher value of } \\
\text { un-capped, 10-year PTA } \\
\text { supports more and larger CSS } \\
\text { projects }\end{array}$ \\
\hline Increasing PTA schedule & $\begin{array}{l}\text { Moderate: PTA cap removal } \\
\text { and extension to } 10 \text { years } \\
\text { increases costs, but increasing } \\
\text { PTA schedule reduces the NPV } \\
\text { of foregone tax revenue }\end{array}$ & $\begin{array}{l}\text { Moderate: Higher value of the } \\
\text { increasing PTA schedule } \\
\text { supports more and larger CSS } \\
\text { projects, but building owners } \\
\text { realize less value early in the } \\
\text { PTA term }\end{array}$ \\
\hline $\begin{array}{l}\text { Commercial expansion program } \\
\text { extension to CSS }\end{array}$ & $\begin{array}{l}\text { High: Foregone tax revenue is } \\
\text { higher due to the structure of } \\
\text { the Commercial Expansion } \\
\text { Program, tying the abatement } \\
\text { amount to rooftop size }\end{array}$ & $\begin{array}{l}\text { High: Higher value of the } \\
\text { Commercial Expansion Program } \\
\text { supports more and larger CSS } \\
\text { projects relative to all other } \\
\text { scenarios. }\end{array}$ \\
\hline
\end{tabular}


The results presented here represent a high-level analysis to inform policymaking. Ranges are presented to avoid over-stating confidence in the results. All results are sensitive to the underlying assumptions (see Appendix A: Methods). In general, the results indicate that NYC could facilitate local CSS deployment through tax incentives on the order of tens of millions of dollars annually. NYC incentives could support CSS capacity additions at the MW scale, resulting in incremental output on the order of tens of thousands of MWh per year. These incentives would also generate local economic activity on the order of millions of dollars per year. 


\section{References}

The City of New York. 2014. "One City Built to Last."

https://www1.nyc.gov/site/builttolast/index.page.

Fu, R., et al. 2017. "U.S. Solar Photovoltaic System Cost Benchmark: Q1 2017.” NREL/TP-

6A20-68925. Golden, CO: National Renewable Energy Laboratory.

https://www.nrel.gov/docs/fy17osti/68925.pdf

NYC. 2018. Selected Initial Findings of the 2017 New York City Housing and Vacancy Survey.

NY PSC. 2015. Case 15-E-0082: Order Establishing a Community Distributed Generation Program and Making Other Findings.

NYSERDA (New York State Energy Research and Development Authority). 2018. "NY-Sun

Program." https://www.nyserda.ny.gov/All-Programs/Programs/NY-Sun. Accessed 1/19/2018.

U.S. Census. 2012. "Patterns of Metropolitan and Micropolitan Population Change: 2000 to 2010." https://www.census.gov/library/publications/2012/dec/c2010sr-01.html.

U.S. Census. 2015. "2013 American Housing Survey." https://www.census.gov/programssurveys/ahs/data.2013.html. 


\section{Appendix A: Methods}

This appendix summaries assumptions and methods used in the policy analysis.

\section{NPV of Foregone Revenue}

Net present values (NPV) are calculated using an assumed discount rate of $3.5 \%$.

\section{Scenario 1: PTA Extension}

Based on stakeholder feedback, we assume a CSS deployment range of $3 \mathrm{MW} /$ year (5 projects) to $7 \mathrm{MW} /$ year (12 projects) under a PTA extension. We assume that half of this deployment would have occurred in a baseline scenario. We conservatively assume that all of the projects would receive the full $\$ 62,500 /$ year abatement. The full NPV of foregone tax revenue is estimated by:

$$
F R=\# \text { of projects } \times \frac{\$ 62,500}{\text { project }} \times\left(\frac{1-(1.035)^{4}}{0.035}\right)
$$

\section{Scenario 2: Reformed PTA Extension}

To estimate the effects of a reformed PTA extension, we estimate the effects of the reformed PTA extension on the NPV of tax incentives accruing to building owners. For illustrative purposes, consider a $500-\mathrm{kW}$ system with a total installed cost of $\$ 2.6 / \mathrm{W} .{ }^{15} \mathrm{We}$ assumed that the system receives $\$ 0.5 / \mathrm{W}$ in state rebates, ${ }^{16}$ so that the PTA-eligible system cost is $\$ 2.1 / \mathrm{W}$. The NPV of this abatement is equal to:

$$
N P V_{S C 1}=500 \mathrm{~kW} \times \frac{\$ 2,100}{k W} \times 5 \% \times\left(\frac{1-(1.035)^{4}}{0.035}\right)=\$ 192,800
$$

Under the reformed PTA extension, the cap is removed and the duration is extended from four to 10 years. The NPV of the PTA for the same $500 \mathrm{~kW}$ system is now:

$$
N P V_{S C 2}=500 \mathrm{~kW} \times \frac{\$ 2,100}{k W} \times 5 \% \times\left(\frac{1-(1.035)^{10}}{0.035}\right)=\$ 436,600
$$

Equations (2) and (3) show that the NPV of the reformed PTA is about 2.3 times higher than the existing PTA for a hypothetical $500 \mathrm{~kW}$ system. This value differential is used to assume that the reformed PTA would increase CSS deployment by a factor of 2.3 in a high-impact policy scenario.

\footnotetext{
${ }^{15}$ Based on the average system cost for pipeline NYC CSS projects reported in the NYSERDA Solar Electric Programs data.

${ }^{16}$ Based on estimate from NYC Mayor's Office of Sustainability.
} 
The NPV of foregone revenue from the reformed PTA extension is calculated:

$$
F R_{S C 2}=k W \text { deployed } \times \frac{\$ 2,100}{k W} \times 5 \% \times\left(\frac{1-(1.035)^{10}}{0.035}\right)
$$

\section{Scenario 3: Increasing PTA Schedule}

The value of the increasing PTA schedule for a hypothetical $500 \mathrm{~kW}$ system with a total installed cost of $\$ 1.05$ million (based on $\$ 2.1 / \mathrm{W}$ cost) under the increasing PTA schedule is calculated:

$$
N P V_{S C 3}=\frac{1 \%(\$ 1.05 M)}{1.035}+\frac{2 \%(\$ 1.05 M)}{1.035^{2}}+\frac{3 \%(\$ 1.05 M)}{1.035^{3}}+\frac{4 \%(\$ 1.05 M)}{1.035^{4}}+\sum_{t=5}^{10} \frac{5 \%(\$ 1.05 M)}{1.035^{t}}=\$ 338,500
$$

Comparing Equations (5) and (2) suggests that the value of the increasing PTA to the building owner is about 1.8 times higher than the value of the existing PTA. This value differential is used to estimate the effects of the increasing PTA on CSS deployment in a high-impact scenario.

The NPV of foregone revenue for Scenario 3 is estimated:

$$
F R_{S C 3}=\frac{1 \% T C}{1.035}+\frac{2 \% T C}{1.035^{2}}+\frac{3 \% T C}{1.035^{3}}+\frac{4 \% T C}{1.035^{4}}+\sum_{t=5}^{10} \frac{5 \% T C}{1.035^{t}}
$$

Where TC equals total costs, based on assumed PTA-eligible costs of $\$ 2.1 / \mathrm{W}$.

\section{Scenario 4: Commercial Expansion Program}

We assume that $15 \mathrm{~W}$ of PV capacity are installed per square foot of rooftop space. Based on this assumption, the value of the Commercial Expansion Program for a hypothetical $500 \mathrm{~kW}$ system is given:

$$
N P V_{S C 4}=500 \mathrm{~kW} \times \frac{s q f t}{0.015 \mathrm{~kW}} \times \frac{\$ 2.5}{s q f t} \times\left(\frac{1-(1.035)^{10}}{0.035}\right)=\$ 693,100
$$

Comparing Equations (7) and (2) suggests that the value of the Commercial Expansion Program to the building owner is about 3.6 times higher than the value of the existing PTA. This value differential is used to estimate the effects of the increasing PTA on CSS deployment in a highimpact scenario.

The NPV of foregone revenue for Scenario 4 is estimated:

$$
F R_{S C 4}=k W \text { deployed } \times \frac{s q f t}{0.015 k W} \times \frac{\$ 2.5}{s q f t} \times\left(\frac{1-(1.035)^{10}}{0.035}\right)
$$




\section{Economic Activity}

Estimates for local economic activity are based on NREL benchmarked costs for commercialscale (10 kW-2 MW) projects (Fu et. al. 2017). NREL estimates un-burdened (before benefits) installation labor costs of $\$ 0.136 / \mathrm{W}$ for commercial-scale projects in New York State. According to data from the U.S. Bureau of Labor Statistics, weekly wages for electricians are about $42 \%$ higher in NYC than in the rest of New York State. Given that some of this difference may reflect burden, we conservatively assume that contractor wages are $20 \%$ higher in NYC than in the rest of the state and adjust the assumed installation labor cost to $\$ 0.16 / \mathrm{W}$. NREL estimates EPC overhead at $\$ 0.17 / \mathrm{W}$ and developer costs at $\$ 0.38 / \mathrm{W}$ for commercial-scale projects in New York State. To the extent that EPC and developer firms are NYC-based, economic activity should also reflect profit margins. We conservatively exclude profit margins given that some engineering, procurement, and construction (EPC) and developer services may be undertaken by firms based outside of NYC. Total local EPC and developer costs are therefore assumed to be $\$ 0.55 / \mathrm{W}$. Full local economic activity is assumed to be $\$ 0.71 / \mathrm{W}$. We believe this is a conservative assumption, excluding indirect local economic activity such as roof replacement that may be associated with NYC CSS projects. Note that economic activity estimates are based on the incremental capacity induced by policy changes, excluding economic activity that would have occurred in the baseline. 